\title{
Enhanced Selective Production of Arenes and Regenerating Rate in Aryl Ether Hydrogenolysis over Mesoporous Nickel in Plug-Flow Reactors
}

\author{
Chunming Zheng ${ }^{1,2, *}$, Dongxue Wang ${ }^{1}$, Xudong $\mathrm{Hu}^{3,4}{ }^{3}$, Chao Ma ${ }^{1}$, Xuan Liu ${ }^{1}$, Ying Wang ${ }^{2}(\mathbb{D}$, \\ Yinkui $\mathrm{Yu}^{2}$, Jiaqi Wang ${ }^{3}$ and Xiaohong Sun ${ }^{3,4, *}$ \\ 1 State Key Laboratory of Separation Membrane and Membrane Processes, School of Chemistry and Chemical \\ Engineering, Tianjin Key Laboratory of Green Chemical Technology and Process Engineering, \\ Tianjin Polytechnic University, Tianjin 300387, China; wangdxtj@foxmail.com (D.W.); \\ 1631151238@stu.tjpu.edu.cn (C.M.); 1731135460@stu.tjpu.edu.cn (X.L.) \\ 2 Department of Chemical Engineering, University of California, Santa Barbara, CA 93106, USA; \\ ywang05@ucsb.edu (Y.W.); yorkyu16@gmail.com (Y.Y.) \\ 3 Department of Chemistry \& Biochemistry, University of California, Santa Barbara, CA 93106, USA; \\ huxd@ucsb.edu (X.H.); jiaqiwang@ucsb.edu (J.W.) \\ 4 School of Materials Science and Engineering, Key Laboratory of Advanced Ceramics and Machining \\ Technology of Ministry of Education, Tianjin University, Tianjin 300072, China \\ * Correspondence: zhengchunming@tjpu.edu.cn (C.Z.); sunxh@tju.edu.cn (X.S.); Tel.: +86-22-83955661 (C.Z.)
}

Received: 16 October 2019; Accepted: 25 October 2019; Published: 29 October 2019

\begin{abstract}
Ordered mesoporous nickel (mesoNi) was successfully synthesized with a hard templating method by using KIT- 6 ordered mesoporous silica as a template. With small-angle X-ray diffraction (SAXRD), transmission electron microscopy (TEM) and $\mathrm{N}_{2}$ sorption technique, the mesoporous structures of synthesized catalysts were characterized with desired high surface area $\left(84.2 \mathrm{~m}^{2} \cdot \mathrm{g}^{-1}\right)$ and narrow pore size distribution. MesoNi exhibited outstanding catalytic cleavage activity for lignin model compounds (benzyl phenyl ether, BPE) with high selectivity of arenes in the flow reactor system. MesoNi also showed higher regeneration rates than non-porous ones, which were confirmed from deactivation and regeneration mechanism studies in the flow reaction system with varied high temperature and pressure. The adsorbed poisoning species on the mesoporous Ni surface were analyzed and phenol could be the main poisoning species. The excellent catalytic cleavage performance of mesoNi originates from their unique mesoporous structure, which offers high surface area and Ni active sites. The outstanding catalytic performance shows that this process provides a promising candidate for improved lignin valorization with general applicability.
\end{abstract}

Keywords: ordered mesoporous nickel; hydrogenolysis; aryl ether; arene; regeneration

\section{Introduction}

Increased demand for energy and value-added chemicals has motivated the development of lignocellulose, which consists of cellulose, hemicellulose, and lignin [1]. Lignin comprises $15-30 \mathrm{wt} \%$ of biomass and ca. $40 \%$ of its total energy content, its potential as a renewable source of aromatic compounds has recently received great attention [2,3]. Lignin remains the least utilized component of lignocellulose, which has a three-dimensional, highly cross-linked, polyphenolic polymer [4,5]. Recently, a number of homogeneous catalysts (e.g., complexes of Ru [6], V [7], and $\mathrm{Ni}$ [8]) and heterogeneous catalysts (e.g., $\mathrm{Ni} / \mathrm{SiO}_{2}$ [9], $\mathrm{Ru} / \mathrm{Nb}_{2} \mathrm{O}_{5}$ [10], and $\mathrm{Pd} / \mathrm{Zn}$ [11]) have shown high hydrogenolytic performance in cleaving the $\mathrm{C}-\mathrm{O}$ bonds of lignin and related dimeric lignin model compounds under mild conditions. Homogeneous catalysts can readily access ether bonds 
in insoluble lignin due to their high mobility, which increases the hydrogenolytic activity of these catalysts [12]. In contrast, heterogeneous catalysts are better adapted to continuous processing [13]. Furthermore, heterogeneous depolymerization of soluble lignin in a flow reactor could enhance heat and mass transfer, allow for variable contact times, and improve the selectivity and yield for desired products $[14,15]$. All of these advantages for heterogeneous hydrogenolytic processes may also serve to improve our understanding of reaction kinetics for $\mathrm{C}-\mathrm{O}$ cleavage of lignin and lignin model compounds [16].

Ni-based catalysts are widely studied for $\mathrm{C}-\mathrm{O}$ bond cleavage in lignin model compounds, such as benzyl phenyl ether (BPE, modeling the lignin $\alpha-\mathrm{O}-4$ linkage), selectively and quantitatively to form smaller aromatic molecules, cycloalkanes, and cyclohexanol under varied temperature and pressure conditions $[17,18]$. Reductive lignin depolymerization with Ni-based catalysts in a flow-through system was also carefully investigated in which pulping and transfer hydrogenolysis steps were conducted in sequence [19]. However, the catalysts activity declines over time. Heterogeneous catalysts for the hydrogenolysis of lignin aryl ethers suffer from deactivation during extended reaction processes. Fundamental understanding of catalyst fouling and regeneration induced by reactants and products need to be addressed [12,20,21]. Using temperature-programmed desorption (TPD) under high-pressure liquid-phase flow conditions, several adsorbed species could be detected during the hydrogenolysis of benzyl phenyl ether (BPE). These species, such as phenol and cyclohexanol, may be responsible for catalyst deactivation in the form of poisoning deposition on the catalyst surface [22]. Hence, the regeneration rate of a Ni-based catalyst is influenced by the nature of the catalyst and the regeneration operating conditions [23].

In this study, we report ordered mesoporous $\mathrm{Ni}$ (mesoNi) produced by the replication of KIT- 6 ordered mesoporous silica as a hard template for the first time. KIT-6 ordered mesoporous silica is a highly ordered mesoporous silica, which has two sets of enantiomeric interwoven mesopores with branched nanorods. The mesoNi showed an enhanced selectivity for arenes during the hydrogenolysis of BPE, which could be important for narrowing the distribution of aromatic monomers in lignin depolymerization. The effect of mesopore morphology on selectivity and stability was investigated and compared with non-porous Raney Ni. The ordered mesoporous Ni showed higher regeneration rates than non-porous Raney $\mathrm{Ni}$, which could be confirmed from the regenerating studies in the flow reaction system with varied high temperature and pressure. The adsorbed poisoning species on the $\mathrm{Ni}$ catalysts surface were analyzed and phenol could be the main species that poisons the surface, which could be removed by increasing the reaction temperature. Thus, deactivation can be reduced substantially by performing hydrogenolysis of aryl ether under appropriate operating conditions.

\section{Results and Discussion}

\subsection{Characterizations of the Catalysts}

Representative SEM images of ordered mesoporous Ni catalysts are shown in Figure 1a. A non-porous Raney Ni catalyst with similar particle size was also synthesized with a hydrothermal method to compare with mesoNi. From Figure 1a, almost all of the mesoporous Ni nanoparticles were in regular spherical shape, which was totally different from their parent KIT-6 template (Figure S1). From Figure 1b, mesoNi samples had a sphere-like morphology, which was crystallized in a similar direction and lattice fringes of the walls were around several small mesopores [24]. Combined with the small-angle X-ray diffraction (SAXRD) results in Figure S2, the intense peak around $1.15^{\circ}$ corresponds to the (211) diffraction of Ia3d symmetry, which indicated the whole mesoNi nanoparticle remained in the long-range mesostructured regularity of the KIT- 6 template $[25,26]$. Figure $1 c$ shows the XRD patterns of mesoNi and Raney Ni displayed typical peaks at $2 \theta=44.5^{\circ}, 51.9^{\circ}$, and $76.4^{\circ}$ which were readily indexed to (111), (200), and (220) reflections of pure metallic Ni (JCPDS card No. 65-0380) [27]. The average crystallite size of mesoNi and Raney Ni were calculated to be 13.7 and $19.6 \mathrm{~nm}$ by using the full-width at half-maximum (fwhm) of the (111) reflection. No obvious diffraction peaks in the 
$\mathrm{Ni}$ catalyst were observed for other $\mathrm{Ni}$ species such as $\mathrm{NiO}$ and silica, which indicated high purity and decreased crystallinity of these catalysts. After the hydrogenolysis of BPE, the diffraction peaks of the reused Ni-based catalysts increased which indicated the crystal growth of the Ni particles. However, there was no other obvious change of diffraction peaks, which also indicated the catalyst remained at similar purity after the reaction.
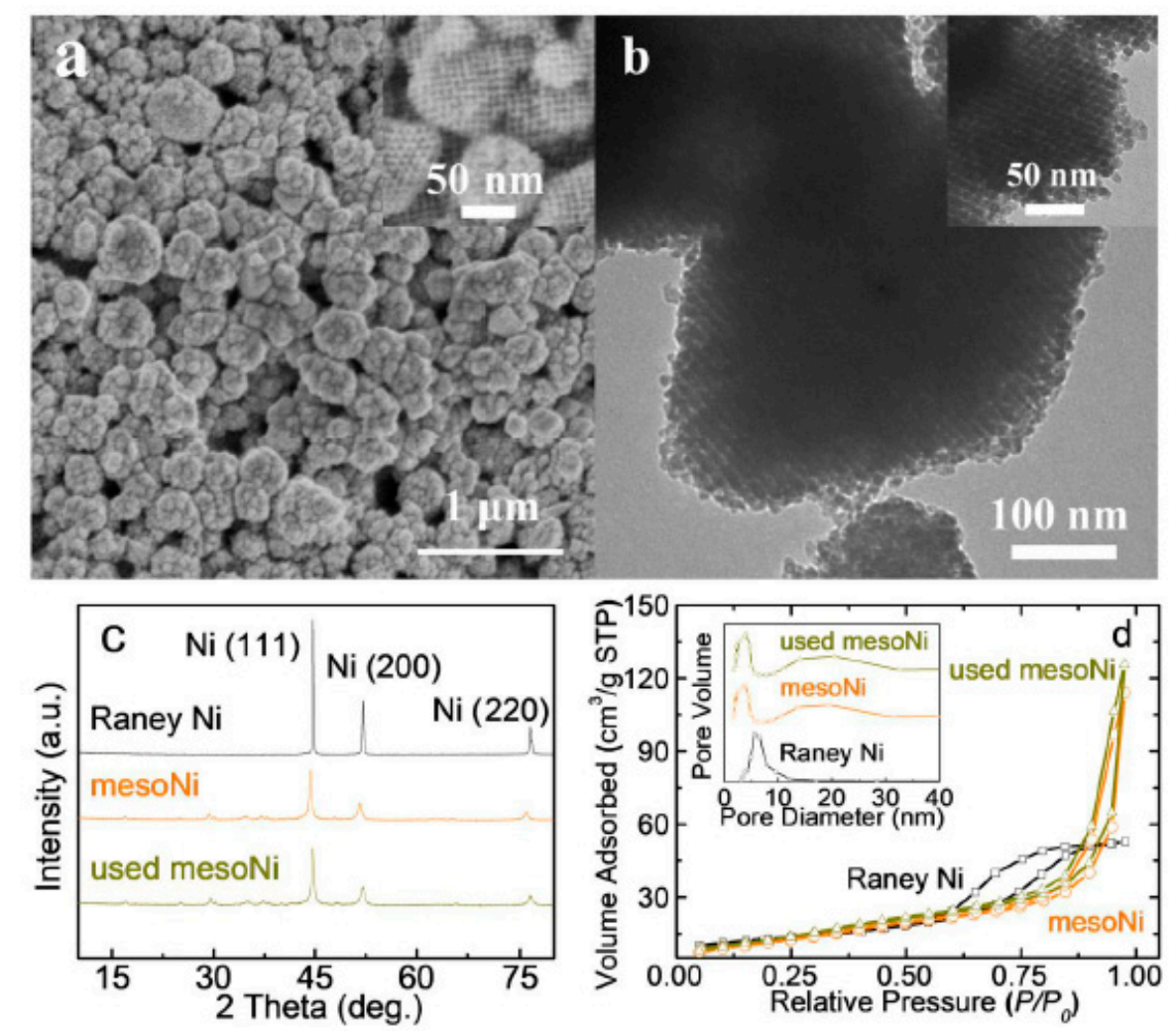

Figure 1. (a) Scanning electron microscope (SEM) images and (b) transmission electron microscope (TEM) images of ordered mesoporous Ni made with KIT-6 ordered mesoporous silica as a hard template (mesoNi), (c) high-angle XRD patterns, and (d) related $\mathrm{N}_{2}$-sorption characterizations of Raney $\mathrm{Ni}$, mesoNi, and used mesoNi. The insets in (a) and (b) show high resolution images of mesoNi.

As Figure 1d illustrates, the isotherms of mesoNi were classical type-IV isotherms with $\mathrm{H} 1$ hysteresis loop, which is the characteristic of mesoporous structure and wide mesopore size distribution [28]. Two pore size distributions of 4.5 and $22 \mathrm{~nm}$ could be observed for mesoNi, of which the former pore was the hard-template replica from KIT- 6 and the latter came from the aggregation of mesoporous particles [24,29]. The Brunauer-Emmett-Teller (BET) surface area and average pore diameter of the Ni-based catalysts are listed in Table 1 . All the specific surface areas of Ni-based catalysts were lower than the parent KIT- 6 template, attributed to the lower structural order and larger density [30]. For used mesoNi, exposure to reaction conditions caused little changes for the porous structures characterized from $\mathrm{N}_{2}$-sorption results. However, these physicochemical changes did not result in significant changes to the powder XRD pattern compared with fresh mesoNi. From the inductive coupled plasma atomic emission spectrometer (ICP-AES) results of $\mathrm{Na}$ and $\mathrm{Si}$ in Table 1, the sodium contents of fresh mesoNi catalysts were lower than $0.02 \mathrm{wt} \%$. After the recycling of the mesoNi, the Na content decreased to $0.01 \mathrm{wt} \%$. The Si content also showed similar trends with Na. Related energy dispersive X-ray spectrometry (EDX) analysis, in association with ICP-AES characterization could further analyze the elemental content of the recycled mesoNi surface. The above results indicated the mesoporous remained of similar purity after the reaction. 
Table 1. The structural and chemical properties of ordered mesoporous $\mathrm{Ni}$ and related Ni-based catalysts and templates.

\begin{tabular}{|c|c|c|c|c|c|c|c|c|}
\hline Catalysts & $\begin{array}{c}\mathrm{S}_{\mathrm{BET}}{ }^{\mathrm{a}} \\
\left(\mathrm{m}^{2} \cdot \mathrm{g}^{-1}\right)\end{array}$ & $\begin{array}{l}D_{p}^{b} \\
(n m)\end{array}$ & $\begin{array}{l}\text { Pore Volume } \\
\left(\mathrm{cm}^{3} \cdot \mathrm{g}^{-1}\right)\end{array}$ & $\begin{array}{l}d_{\text {XRD }} \\
(\mathrm{nm})\end{array}$ & $\begin{array}{l}\mathrm{d}_{\text {TEM }} \\
(\mathrm{nm})\end{array}$ & $\mathrm{Na}^{\mathrm{c}}{ }^{\mathrm{wt}} \%$ & Si wt $\%$ & $\begin{array}{c}\text { Ni Leaching } \\
\left(\mathrm{mg} \cdot \mathrm{L}^{-1}\right)\end{array}$ \\
\hline MesoNi & 84.2 & 8.9 & 0.191 & 13.7 & $268 \pm 64$ & 0.02 & 0.13 & $<0.1$ \\
\hline Raney Ni & 46.3 & 5.6 & 0.082 & 19.6 & $576 \pm 83$ & $\mathrm{~N} / \mathrm{D}$ & $\mathrm{N} / \mathrm{D}$ & $<0.1$ \\
\hline Recycled mesoNi & 87.7 & 9.9 & 0.217 & 16.2 & $293 \pm 73$ & 0.01 & 0.07 & $<0.1$ \\
\hline KIT-6 template & 803 & 2.3 & 0.602 & - & - & - & - & - \\
\hline
\end{tabular}

a $\mathrm{S}_{\mathrm{BET}}$ : Surface area calculated by Brunauer-Emmett-Teller (BET) method. ${ }^{\mathrm{b}} \mathrm{D}_{\mathrm{p}}$ : Barrett-Joyner-Halanda (BJH) average pore size calculated on the desorption branch of $\mathrm{N}_{2}$ isotherm. ${ }^{\mathrm{c}}$ Actual sodium and silicon content in catalysts $(\mathrm{wt} \%)$ determined by inductive coupled plasma atomic emission spectrometer (ICP-AES) analysis. N/D stands for not detected. ${ }^{\mathrm{d}}$ Dissolved sodium and silicon content in solution after reaction determined by ICP-AES analysis.

\subsection{Catalytic Hydrogenolysis of $B P E$}

The conversion of BPE on ordered mesoporous $\mathrm{Ni}$ as a function of space time (W/F) is compared with Raney Ni in Figure 2a. For Raney Ni with large particle size, the conversion of BPE achieved $96 \%$ at a high space time of $6.5 \mathrm{~h}$. The mesoNi showed much higher conversion (>99\% in $0.9 \mathrm{~h}$ ) compared to Raney Ni. This result suggests that the mesoNi catalyst was more active than non-porous Raney Ni for hydrogenolysis of BPE [31]. Figure $2 \mathrm{~b}$ shows the major product distribution as a function of hydrogenolysis conversion of BPE on mesoNi and Raney Ni. Consistent with previous work, phenol $(\mathrm{PhOH})$ and toluene $(\mathrm{Tol})$ are the primary products of hydrogenolysis over all catalysts. These products could then be hydrogenated to cyclohexanol $(\mathrm{CyOH})$ and methylcyclohexane $(\mathrm{MCH})$ (Scheme S1). From Figure 2b, mesoNi showed much higher selectivity for $\mathrm{PhOH}$. $\mathrm{CyOH}$ was only generated when mesoNi was used under a high conversion level above $20 \%$, which indicated the selectivity of these reactions was strongly dependent on the porous structures of Ni-based catalysts. From the selectivity to primary products at certain low conversion level of $20 \% \pm 2 \%$ (Figure 2c), mesoNi gave the higher yield of $\mathrm{PhOH}$ compared to Raney $\mathrm{Ni}$, which also meant a higher hydrogenolysis efficiency for BPE. Changing the catalyst structure from mesoporous to non-porous led to a significant decrease in the selectivity toward $\mathrm{C}-\mathrm{O}$ hydrogenolysis. The apparent activation energy $\left(\mathrm{E}_{\mathrm{a}, \mathrm{app}}\right)$ of liquid phase hydrogenolysis of BPE for non-porous Raney Ni and mesoNi is shown in Figure 2d. The mesoNi showed the lowest $E_{a, a p p}$ of $71 \mathrm{KJ} / \mathrm{mol}$. The apparent activation energy of phenol hydrogenation to cyclohexanol was higher than that of hydrogenolysis of BPE $(89 \mathrm{KJ} / \mathrm{mol}$ compared to $71 \mathrm{KJ} / \mathrm{mol}$, Figure S3), which indicated the elevated temperature was beneficial to increase the selectivity of cyclohexanol [32].

The above differences clearly indicate that changing the porous structure of the Ni-based catalyst could remarkably change the selectivity towards different reaction pathways. Consequently, changing Ni-based catalysts from non-porous to mesoporous structure could dramatically improve hydrogenolysis efficiencies to BPE while it greatly inhibits hydrogenation of phenyl rings.

In order to study the regeneration processes and stability of the mesoNi and Raney Ni catalysts, the reusage activities of hydrogenolysis of BPE with these catalysts was examined in batch at $120^{\circ} \mathrm{C}$ for six runs. As Figure 3a displays, BPE conversion of all catalysts decreased with increasing recycling batch runs. For mesoNi, BPE conversion decreased about $7 \%$ after six runs, which demonstrates the mesoNi had higher recycling abilities and stabilities than non-porous Raney Ni. From ICP analysis of the products solution, no detectable amount of Ni leached out of the catalyst during the reactions (Table 1). For the hydrogenolysis of BPE, poisoning and fouling of the Ni-based catalysts could be the main reason for the deactivation during the reaction process [22,23]. Hence, metal leaching is not the main reason for catalyst deactivation and quite limited $\mathrm{Ni}$ concentration $\left(<0.1 \mathrm{mg} \cdot \mathrm{L}^{-1}\right)$ was detected in the reaction products. To further study the regeneration mechanism, the deactivated catalysts were washed with pure isopropanol to remove the residual products and then regenerated at $205^{\circ} \mathrm{C}$ with $5.0 \mathrm{mmol} \mathrm{L}^{-1} \mathrm{BPE}$ in isopropanol as the H-donor (Figure $3 \mathrm{~b}$ ). The BPE conversion remained quite low when the regeneration temperature increased to $205^{\circ} \mathrm{C}$. Then the BPE conversion gradually increased and reached the highest value (91.4\% and 96.7\%) with 105 and 89 min for Raney $\mathrm{Ni}$ and mesoNi, 
respectively. The deactivation and regeneration of Ni-based catalysts are often associated with the surface adsorption of the organic intermediates and products [33], and these surface adsorbed species have different poisoning effect to the deactivation of the catalysts, which is vital to further investigate the deactivation and regeneration mechanism [34,35].
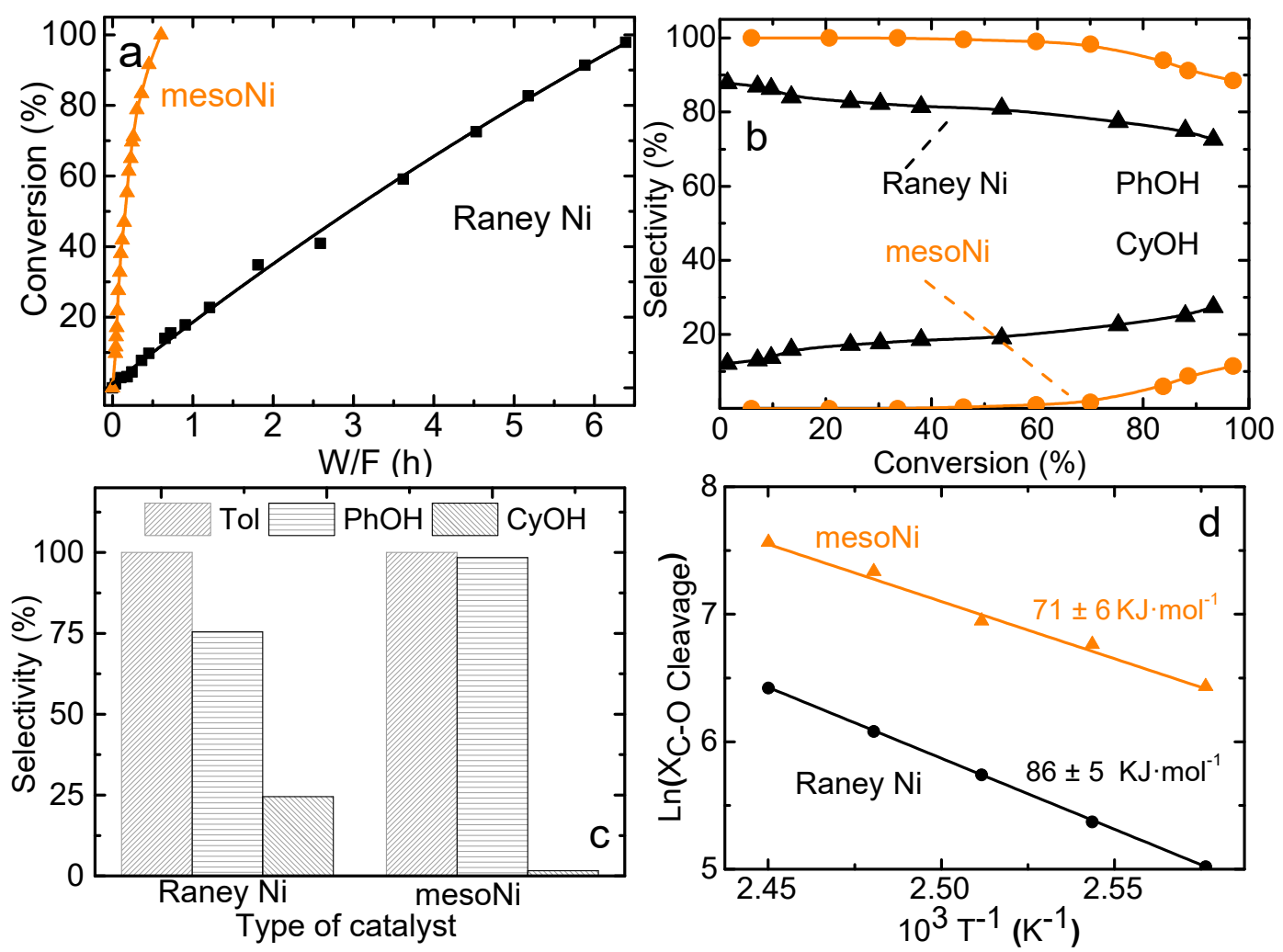

Figure 2. (a) Conversion as a function of space time (W/F) for hydrogenolysis of benzyl phenyl ether (BPE) and (b) major primary product distribution as a function of BPE conversion over mesoNi and Raney Ni catalysts. (c) Selectivity toward major products as W/F was adjusted to maintain a similar BPE conversion level $(20 \% \pm 2 \%)$. (d) Related Arrhenius plots and corresponding apparent activation energies ( $\left.E_{\mathrm{a}, \mathrm{app}}\right)$ for hydrogenolysis of BPE. Reaction conditions: $120^{\circ} \mathrm{C}, 20.0 \mathrm{mg}$ catalyst, 2-propanol as both solvent and $\mathrm{H}$-donor, pressure $4 \mathrm{MPa}, 5.0 \mathrm{mmol} \cdot \mathrm{L}^{-1} \mathrm{BPE}$, Time on Stream $(\mathrm{TOS})=60 \mathrm{~min}$.

To study the regeneration mechanism of Ni-based catalysts, surface adsorption products of BPE hydrogenolysis were analyzed with temperature-programmed desorption under high pressure liquid flow conditions. From Figure 3c, the $\mathrm{CyOH}$ peak of Raney Ni was detected at $180{ }^{\circ} \mathrm{C}(32 \mathrm{~min})$ with temperature increasing and flushing of pure isopropanol. The desorption rate went through a maximum at $205^{\circ} \mathrm{C}(59 \mathrm{~min})$. The $\mathrm{PhOH}$ peak could also be detected at the same temperature, of which the peak area was much lower than that of $\mathrm{CyOH}$. No obvious peak of Tol was detected during the process. Compared to Raney $\mathrm{Ni}$, the $\mathrm{CyOH}$ peak of mesoNi was higher than that of Raney $\mathrm{Ni}$ (Figure 3d). The maximum desorption peak of mesoNi was also earlier than that of Raney Ni. Since both the peaks of $\mathrm{CyOH}$ and $\mathrm{PhOH}$ were detected, it is possible that adsorbed $\mathrm{PhOH}$ was hydrogenated to $\mathrm{CyOH}$ on the $\mathrm{Ni}$ active sites under the high temperature of $205^{\circ} \mathrm{C}$ [34]. Meanwhile, it could not be BPE molecule. If it was BPE adsorbed on the surface of Ni nanoparticles, an equivalent amount of phenol and toluene would have been detected. The concentration of toluene peak was much lower than that of phenol, which meant the adsorbed molecules could not produce an equal amount of phenol and toluene. Thus, it was impossible for BPE molecules to be adsorbed on the catalyst surface. Therefore, the adsorbed molecules were likely phenol molecules [31,36]. Related attenuated total reflectance Fourier transform infrared spectroscopy (ATR FT-IR) was used to characterize the adsorbed species on the Ni nanoparticles (shown in Figure S4). 
Figure S4 compares IR spectra of adsorbed species formed on the deactivated Ni-based catalysts after the hydrogenolysis of BPE. Unlike the corresponding spectra of pure mesoNi or BPE, the spectrum of deactivated mesoNi showed the diagnostic absorption of cyclohexanol species at $3332 \mathrm{~cm}^{-1}$ and $2965 \mathrm{~cm}^{-1}$. These two peaks as well as relevant absorption in the stretching and bending of $\mathrm{O}-\mathrm{H}$ and C-H bonds (3400 3650 and 2850 2960 $\mathrm{cm}^{-1}$ ) were evident in the spectra obtained for cyclohexanol. It is worth emphasizing neither of these absorptions was observed when pure mesoNi was tested. The absorption peaks at 948 and $1013 \mathrm{~cm}^{-1}$ may help in attributing them to absorbed cyclohexanol surface species on the Ni-based catalysts. Finally, formation of surface cyclohexanol has been considered a consequence of phenol surface reactions on metal nanoparticles [37]. These results confirm the desorption results of poisoning species on the Ni-based catalysts shown in Figure 3.
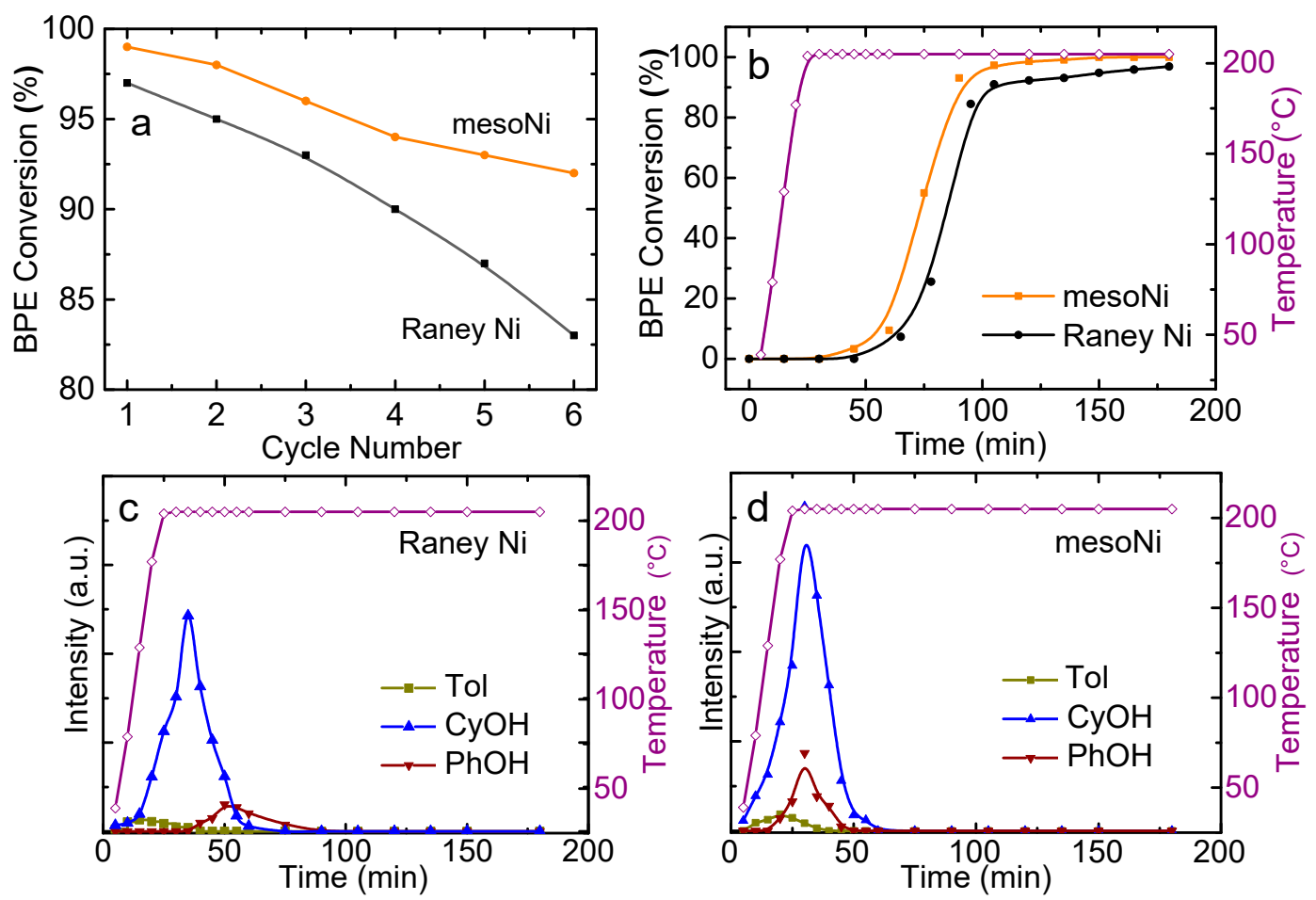

Figure 3. (a) Recycling of mesoNi and Raney $\mathrm{Ni}$ catalysts used in batch benzyl phenyl ether (BPE) hydrogenolysis. Reaction conditions: $120{ }^{\circ} \mathrm{C}, 20.0 \mathrm{mg}$ catalyst, $80 \mathrm{~mL}$ 2-propanol (2-PrOH) as both solvent and $\mathrm{H}$-donor, pressure $4 \mathrm{MPa}, 5.0 \mathrm{mmol} \cdot \mathrm{L}^{-1} \mathrm{BPE}$, stirring at $650 \mathrm{rpm}$. (b) Temperature-programmed regeneration of the used mesoNi and Raney Ni catalysts in a flow reactor. Regeneration conditions: $25-205^{\circ} \mathrm{C}, 10^{\circ} \mathrm{C} \cdot \mathrm{min}^{-1}, 20.0 \mathrm{mg}$ catalyst, 2-PrOH as both solvent and $\mathrm{H}$-donor, pressure $4 \mathrm{MPa}, 5.0 \mathrm{mmol} \cdot \mathrm{L}^{-1} \mathrm{BPE}$. Temperature-programmed desorption from used $\mathrm{Ni}$ catalysts in a flow reactor: (c) Raney $\mathrm{Ni}$ and (d) mesoNi. Concentrations were measured by Gas chromatograph-flame ionization detector (GC-FID) and normalized using an internal standard. Desorption conditions: $25-205^{\circ} \mathrm{C}, 10^{\circ} \mathrm{C} \mathrm{min}^{-1}, 20.0 \mathrm{mg}$ catalyst, pressure $4 \mathrm{MPa}, 2-\mathrm{PrOH}$ as both solvent and H-donor.

To further investigate the competitive reaction pathways during the reaction processes, hydrogenolysis of BPE were carried out in a mixture with reaction products or analogous phenolic monomers at $120^{\circ} \mathrm{C}$ (Figure 4a) [35,38]. From Figure 4a, the conversion of BPE hydrogenolysis achieved $71 \%$ after $30 \mathrm{~min}$. However, the conversion of BPE hydrogenolysis progressively varied in the presence of toluene (60\%), cyclohexanol (56\%), and phenol $(24 \%)$ after $30 \mathrm{~min}$ (Figure $4 \mathrm{~b}$ ). Therefore, the addition of $\mathrm{PhOH}$ obviously decreased the BPE conversion compared to Tol and $\mathrm{CyOH}$. Moreover, the hydrogenation rate for $\mathrm{PhOH}$ was much faster than that of Tol, which indicated the higher reactivity and lower active energy of $\mathrm{PhOH}$ hydrogenation. When equimolar phenol was added to the BPE solution, competitive adsorption could have happened between the added phenol and 
the phenol generated from the hydrogenolysis of BPE (Figure 4c) [39]. Hence, the hydrogenolysis rate of BPE could be influenced at last [20,40]. However, when the phenol was added to the reaction system, the hydrogenolysis rate of BPE greatly decreased. The hydrogenation rate of phenol was higher than that of toluene since almost no methylcyclohexane was generated during the reaction. Hence, hydrogenolysis of BPE was greatly influenced with the addition of phenol. Compared to Figure $4 c$, the effects of other phenolic monomers formed in lignin disassembly were also analyzed by addition of equimolar catechol, guaiacol, and anisole to the BPE during the hydrogenolysis reactions (Figure $4 \mathrm{~d}$ ). The hydrogenolysis rate of BPE was the most affected by the addition of catechol and anisole showed the least hinderance effect analyzed from kinetic profiles [41]. These results analyzed together with those relative to chemical species generated in the reaction, implied that the hydrogenolysis process of BPE was very sensitive to the presence of analogous phenolic monomers in the reaction system.
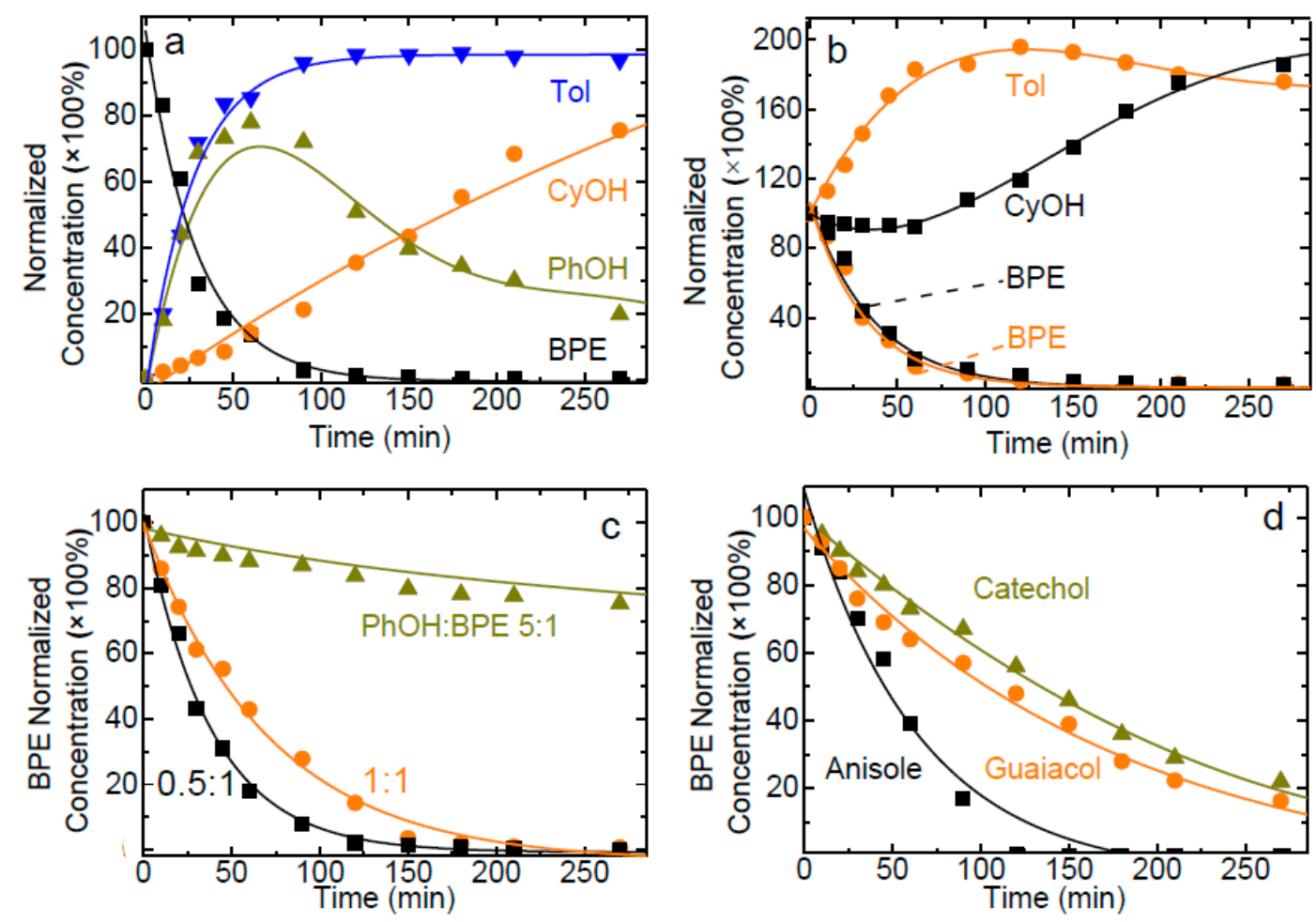

Figure 4. Kinetic profiles for benzyl phenyl ether (BPE) hydrogenolysis with mesoNi in a batch reactor: (a) with no reaction products, (b) in the presence of a reaction product (toluene or cyclohexanol, 1 equiv.), (c) in the presence of various amounts of phenol (5, 1, and 0.5 equiv.); (d) in the presence of anisole, catechol or guaiacol (1 equiv.). Normalized concentrations were measured by GC-FID using an internal standard. Reaction conditions: $120^{\circ} \mathrm{C}, 20.0 \mathrm{mg}$ catalyst, $80 \mathrm{~mL}$ 2-PrOH as both solvent and H-donor, pressure $4 \mathrm{MPa}, 5.0 \mathrm{mmol} \mathrm{L}^{-1} \mathrm{BPE}$, stirring at $650 \mathrm{rpm}$.

\section{Materials and Methods}

\subsection{Preparation of Catalysts}

Ordered mesoporous $\mathrm{Ni}$ catalysts were synthesized using a modified dipping method to improve the long-range ordering according to the template direction [42,43]. Typically, $0.078 \mathrm{~g}$ of hexamethyldisilazane (HMDS) was added into $30 \mathrm{~mL}$ of $\mathrm{n}$-hexane with $0.40 \mathrm{~g}$ of calcined KIT- 6 to modify the silica surface of KIT-6 with methyl groups by refluxing. The obtained material was denoted as hydrophobic KIT-6 (HP-KIT-6). Then, absolute ethanol solution $\left(0.21 \mathrm{~g}\right.$ of $\mathrm{Ni}\left(\mathrm{NO}_{3}\right)_{2} \cdot 6 \mathrm{H}_{2} \mathrm{O}$, $3 \mathrm{~mol} \cdot \mathrm{L}^{-1}$ ) was impregnated into $0.35 \mathrm{~g}$ of the HP-KIT- 6 . After drying at $40^{\circ} \mathrm{C}$ for two days, the sample was heated to $350^{\circ} \mathrm{C}$ in air for $2 \mathrm{~h}$ with heating rate of $1{ }^{\circ} \mathrm{C} \cdot \mathrm{min}^{-1}$. Then, the products were collected 
and placed in the tubular furnace, and further reduced at a higher temperature of $450{ }^{\circ} \mathrm{C}$ under $10 \%$ $\mathrm{H}_{2}+\mathrm{N}_{2}$ mixture gas flow $\left(100 \mathrm{~mL} \cdot \mathrm{min}^{-1}\right)$ for another $2 \mathrm{~h}$ at a heating rate of $1{ }^{\circ} \mathrm{C} \cdot \mathrm{min}^{-1}$. Then, the composite material was treated with $2 \mathrm{~mol} \cdot \mathrm{L}^{-1}$ sodium hydroxide solution $(50 \mathrm{~mL})$ at $40^{\circ} \mathrm{C}$ for $4 \mathrm{~h}$ to completely remove the silica template. After washing with absolute ethanol, the product was further washed with hydrazine hydrate ethanol solution $\left(2 \mathrm{~mol} \mathrm{~L}^{-1}, 50 \mathrm{~mL}\right)$ at room temperature for $4 \mathrm{~h}$. The possible oxidized $\mathrm{NiO}$ was also reduced during the process. The final product was washed with absolute ethanol and water several times. After vacuum drying at $60^{\circ} \mathrm{C}$ overnight, the final product was labeled as the mesoNi.

\subsection{Hydrogenolysis of $B P E$}

The flow reactor (1/4 in. outer diameter) was heated with up-flow direction with aluminum heat transfer blocks wrapped in electric heating tape and a ceramic insulating blanket. A K-type thermocouple and a thermal controller was used to control the reaction. The Ni-based catalyst $(20.0 \mathrm{mg})$ was diluted with silicon carbide (180.0 mg, 80-100 mesh, Sigma-Aldrich). Then the above mixture was loaded into the tubular reactor with crushed quartz (0.1-0.2 mm diameter, void fraction 0.4, Sigma-Aldrich) and glass wool to hold the catalyst bed in place (Scheme S1 in Supporting Information). The liquid was fed into the reactor with an HPLC pump (Dalian Elite Co. Ltd., P230II). With the desired reaction condition of flow rate $\left(0.04-10.0 \mathrm{~mL} \mathrm{~min}^{-1}\right)$ and pressure $(0.1-4.0 \mathrm{MPa})$, appreciable conversion of the hydrogenolysis process could be maintained for the kinetics study. The temperature and pressure of liquid reactant was controlled with rapped heating tape and a back pressure regulator located after the reactor. The total pressure of the reactor was monitored with a pressure gauge. After passing through the gas-liquid separator, the collected liquid products were analyzed with gas chromatography-mass spectrometer (GC-MS) (injection volume 1 uL, Shimadzu 2010, Agilent HP-5MS, $30 \mathrm{~m} \times 0.25 \mu \mathrm{m} \times 0.25 \mu \mathrm{m})$. The space time $(\mathrm{W} / \mathrm{F})$ was used as the reciprocal of weight hourly space velocity (WHSV).

\section{Conclusions}

In this study, ordered mesoporous $\mathrm{Ni}$ (mesoNi) was successfully fabricated by using KIT-6 as a hard template and applied for the hydrogenolysis of benzyl phenyl ether (BPE) with 2-propanol as the hydrogen source. MesoNi has a uniform pore structure, which the specific surface area and average pore diameter of the catalyst could reach $84.2 \mathrm{~m}^{2} \cdot \mathrm{g}^{-1}$ and $8.9 \mathrm{~nm}$, respectively. The catalytic system not only presented high hydrogenolysis activity for BPE, but also showed excellent selectivity and enhanced stability for the process. The possible reason relies to the unique mesoporous structure and high specific surface area of mesoNi, which facilitates the mass transport of the lignin model compounds and enhances the heterogeneous hydrogenolysis activities of mesoNi. Arenes and cyclohexanol are the major products for the hydrogenolysis of lignin model compounds. MesoNi also shows good catalytic activities after six cyclic runs without change of structural framework. Phenol could be the main poisoning species after the analysis of adsorbed species on the mesoNi surface. This study provides a highly efficient catalytic system with high selectivity of arenes, which may inspire the lignin valorization to value-added low molecular weight aromatics.

Supplementary Materials: The following are available online at http://www.mdpi.com/2073-4344/9/11/904/s1, Figure S1. (a) Scanning electron microscope (SEM) image and (b) transmission electron microscope (TEM) image of mesoporous silica KIT-6, Figure S2. Small-angle XRD patterns of ordered mesoporous Ni made using KIT-6 as a hard template, before and after use in benzyl phenyl ether (BPE) hydrogenolysis, Figure S3. Arrhenius plot and apparent activation energy $\left(E_{a, a p p}\right)$ for hydrogenolysis of phenol. Reaction conditions: $20.0 \mathrm{mg}$ catalyst, 2-propanol as both solvent and $\mathrm{H}$-donor, pressure $4 \mathrm{MPa}, 5.0 \mathrm{mmol} \cdot \mathrm{L}^{-1} \mathrm{BPE}$, TOS $=60 \mathrm{~min}$, Figure S4. ATR-IR spectra of used Ni-based catalysts compared to cyclohexanol, phenol and benzyl phenyl ether (BPE). Reaction conditions: $120^{\circ} \mathrm{C}, 20.0 \mathrm{mg}$ catalyst, $80 \mathrm{~mL}$ 2-PrOH as both solvent and $\mathrm{H}$-donor, pressure $4 \mathrm{MPa}, 5.0 \mathrm{mmol} \cdot \mathrm{L}^{-1} \mathrm{BPE}$, stirring at $650 \mathrm{rpm}$, Figure S5 EDX characterization of Raney Ni, fresh and used mesoporous nickel catalyst (mesoNi), Scheme S1 Major products over Ni-based catalysts, indicating two sequential reaction pathways: C-O bond hydrogenolysis to toluene and phenol, and subsequent hydrogenation of phenyl ring to methylcyclohexane and cyclohexanol. 
Author Contributions: Conceptualization and methodology, C.Z. and X.S.; investigation and Writing-Original Draft preparation, D.W., X.H., X.L., C.M., Y.W., Y.Y., J.W., and C.Z.; Writing-Review and Editing, X.S.

Funding: This research was funded by the National Natural Science Foundation of China, NSFC (51772208, 51772205), and the General Program of Municipal Natural Science Foundation of Tianjin (17JCYBJC22700, 17JCYBJC17000).

Conflicts of Interest: The authors declare no conflict of interest.

\section{References}

1. Deuss, P.J.; Barta, K. From models to lignin: Transition metal catalysis for selective bond cleavage reactions. Coord. Chem. Rev. 2015, 306, 510-532. [CrossRef]

2. Joseph, Z.; Bruijnincx, P.C.A.; Jongerius, A.L.; Weckhuysen, B.M. The catalytic valorization of lignin for the production of renewable chemicals. Chem. Rev. 2013, 110, 3552-3599.

3. Carrott, P.J.M.S.; Carrott, M.M.L.R. Lignin-From natural adsorbent to activated carbon: A review. Bioresour. Technol. 2007, 98, 2301-2312.

4. Sun, Z.; Fridrich, B.; de Santi, A.; Elangovan, S.; Barta, K. Bright side of lignin depolymerization: Toward new platform chemicals. Chem. Rev. 2018, 118, 614-678. [CrossRef] [PubMed]

5. Upton, B.M.; Kasko, A.M. Strategies for the conversion of lignin to high-value polymeric materials: Review and perspective. Chem. Rev. 2016, 116, 2275-2306. [CrossRef] [PubMed]

6. Nichols, J.M.; Bishop, L.M.; Bergman, R.G.; Ellman, J.A. Catalytic c-o bond cleavage of 2-aryloxy-1-arylethanols and its application to the depolymerization of lignin-related polymers. J. Am. Chem. Soc. 2010, 132, 12554-12555. [CrossRef] [PubMed]

7. Son, S.; Toste, F.D. Non-oxidative vanadium-catalyzed c-o bond cleavage: Application to degradation of lignin model compounds. Angew. Chem. Int. Ed. Engl. 2010, 49, 3791-3794. [CrossRef]

8. Sergeev, A.G.; Hartwig, J.F. Selective, nickel-catalyzed hydrogenolysis of aryl ethers. Science 2011, $42,439$. [CrossRef]

9. Jiayue, H.; Chen, Z.; Lercher, J.A. Ni-catalyzed cleavage of aryl ethers in the aqueous phase. J. Am. Chem. Soc. 2012, 134, 20768.

10. Parsell, T.H.; Owen, B.C.; Klein, I.; Jarrell, T.M.; Marcum, C.L.; Haupert, L.J.; Amundson, L.M.; Kenttämaa, H.I.; Ribeiro, F.; Miller, J.T.; et al. Cleavage and hydrodeoxygenation (hdo) of c-o bonds relevant to lignin conversion using pd/zn synergistic catalysis. Chem. Sci. 2013, 4, 806-813. [CrossRef]

11. Shao, Y.; Xia, Q.; Dong, L.; Liu, X.; Han, X.; Parker, S.F.; Cheng, Y.; Daemen, L.L.; Ramirezcuesta, A.J.; Yang, S. Selective production of arenes via direct lignin upgrading over a niobium-based catalyst. Nat. Commun. 2017, 8, 16104. [CrossRef] [PubMed]

12. Schutyser, W.; Renders, T.; Van den Bosch, S.; Koelewijn, S.F.; Beckham, G.T.; Sels, B.F. Chemicals from lignin: An interplay of lignocellulose fractionation, depolymerisation, and upgrading. Chem. Soc. Rev. 2018, 47, 852-908. [CrossRef] [PubMed]

13. Li, C.; Zhao, X.; Wang, A.; Huber, G.W.; Zhang, T. Catalytic transformation of lignin for the production of chemicals and fuels. Chem. Rev. 2015, 115, 11559-11624. [CrossRef] [PubMed]

14. Lama, S.M.G.; Pampel, J.; Fellinger, T.-P.; Beskoski, V.P.; Slavkovic-Beskoski, L.; Antonietti, M.; Molinari, V. Efficiency of ni nanoparticles supported on hierarchical porous nitrogen-doped carbon for hydrogenolysis of kraft lignin in flow and batch systems. ACS Sustain. Chem. Eng. 2017, 5, 2415-2420. [CrossRef]

15. Anderson, E.M.; Stone, M.L.; Hulsey, M.J.; Beckham, G.T.; Roman-Leshkov, Y. Kinetic studies of lignin solvolysis and reduction by reductive catalytic fractionation decoupled in flow-through reactors. ACS Sustain. Chem. Eng. 2018, 6, 7951-7959. [CrossRef]

16. Yang, S.; Jeong, S.; Ban, C.; Kim, H.; Kim, D.H. Catalytic cleavage of ether bond in a lignin model compound over carbon-supported noble metal catalysts in supercritical ethanol. Catalysts 2019, 9. [CrossRef]

17. Molinari, V.; Clavel, G.; Graglia, M.; Antonietti, M.; Esposito, D. Mild continuous hydrogenolysis of kraft lignin over titanium nitride-nickel catalyst. ACS Catal. 2016, 6, 1663-1670. [CrossRef]

18. Chen, X.; Guan, W.; Tsang, C.-W.; Hu, H.; Liang, C. Lignin valorizations with ni catalysts for renewable chemicals and fuels productions. Catalysts 2019, 9. [CrossRef]

19. Kumaniaev, I.; Subbotina, E.; Sävmarker, J.; Larhed, M.; Galkin, M.V.; Samec, J. Lignin depolymerization to monophenolic compounds in a flow-through system. Green Chem. 2017, 19. [CrossRef] 
20. Yang, F.; Liu, D.; Zhao, Y.; Wang, H.; Han, J.; Ge, Q.; Zhu, X. Size dependence of vapor phase hydrodeoxygenation of m-cresol on ni/sio2 catalysts. ACS Catal. 2018, 8, 1672-1682. [CrossRef]

21. Qi, S.-C.; Zhang, L.; Einaga, H.; Kudo, S.; Norinaga, K.; Hayashi, J.-i. Nano-sized nickel catalyst for deep hydrogenation of lignin monomers and first-principles insight into the catalyst preparation. J. Mater. Chem. A 2017, 5, 3948-3965. [CrossRef]

22. Verhaak, M.J.F.M.; Vandillen, A.J.; Geus, J.W. The deactivation of nickel catalysts in the hydrogenation of acetonitrile. J. Catal. 1993, 143, 187-200. [CrossRef]

23. Baiker, A.; Monti, D.; Fan, Y.S. Deactivation of copper, nickel, and cobalt catalysts by interaction with aliphatic amines. J. Catal. 1984, 88, 81-88. [CrossRef]

24. Sun, X.; Hao, H.; Ji, H.; Li, X.; Cai, S.; Zheng, C. Nanocasting synthesis of in2o3 with appropriate mesostructured ordering and enhanced gas-sensing property. ACS Appl. Mater. Interfaces 2014, 6, 401-409. [CrossRef]

25. Sakamoto, Y.; Kim, T.W.; Ryoo, R.; Terasaki, O. Three-dimensional structure of large-pore mesoporous cubic ia(3)over-bard silica with complementary pores and its carbon replica by electron crystallography. Angew. Chem.-Int. Ed. 2004, 43, 5231-5234. [CrossRef]

26. Hafizi, H.; Chermahini, A.N.; Saraji, M.; Mohammadnezhad, G. The catalytic conversion of fructose into 5-hydroxymethylfurfural over acid-functionalized kit-6, an ordered mesoporous silica. Chem. Eng. J. 2016, 294, 380-388. [CrossRef]

27. Wang, X.; Rinaldi, R. Solvent effects on the hydrogenolysis of diphenyl ether with raney nickel and their implications for the conversion of lignin. ChemSusChem 2012, 5, 1455-1466. [CrossRef]

28. Kleitz, F.; Choi, S.H.; Ryoo, R. Cubic ia3d large mesoporous silica: Synthesis and replication to platinum nanowires, carbon nanorods and carbon nanotubes. Chem. Commun. 2003, 2136-2137. [CrossRef]

29. Chen, P.; Zhang, Q.; Shu, R.; Xu, Y.; Ma, L.; Wang, T. Catalytic depolymerization of the hydrolyzed lignin over mesoporous catalysts. Bioresour. Technol. 2017, 226, 125-131. [CrossRef]

30. Sun, X.; Shi, Y.; Zhang, P.; Zheng, C.; Zheng, X.; Zhang, F.; Zhang, Y.; Guan, N.; Zhao, D.; Stucky, G.D. Container effect in nanocasting synthesis of mesoporous metal oxides. J. Am. Chem. Soc. 2011, 133, 14542-14545. [CrossRef]

31. Zaheer, M.; Hermannsdoerfer, J.; Kretschmer, W.P.; Motz, G.; Kempe, R. Robust heterogeneous nickel catalysts with tailored porosity for the selective hydrogenolysis of aryl ethers. ChemCatChem 2014, 6, 91-95. [CrossRef]

32. Resende, K.A.; Hori, C.E.; Noronha, F.B.; Shi, H.; Gutierrez, O.Y.; Camaioni, D.M.; Lercher, J.A. Aqueous phase hydrogenation of phenol catalyzed by pd and pdag on zro2. Appl. Catal. A-Gen. 2017, 548, 128-135. [CrossRef]

33. Paone, E.; Espro, C.; Pietropaolo, R.; Mauriello, F. Selective arene production from transfer hydrogenolysis of benzyl phenyl ether promoted by a co-precipitated pd/fe3o4 catalyst. Catal. Sci. Technol. 2016, 6, 7937-7941. [CrossRef]

34. Sawhney, B.L. Vapor-phase sorption and polymerization of phenols by smectite in air and nitrogen. Clay Clay Miner. 1985, 33, 123-127. [CrossRef]

35. Luo, Z.; Zheng, Z.; Wang, Y.; Sun, G.; Jiang, H.; Zhao, C. Hydrothermally stable ru/hzsm-5-catalyzed selective hydrogenolysis of lignin-derived substituted phenols to bio-arenes in water. Green Chem. 2016, 18, 5845-5858. [CrossRef]

36. Li, K.; Wang, R.; Chen, J. Hydrodeoxygenation of anisole over silica-supported ni2p, mop, and nimop catalysts. Energ Fuel 2011, 25, 854-863. [CrossRef]

37. Walter, E.D.; Qi, L.; Chamas, A.; Mehta, H.S.; Sears, J.A.; Scott, S.L.; Hoyt, D.W. Operando mas nmr reaction studies at high temperatures and pressures. J. Phys. Chem. C 2018, 122, 8209-8215. [CrossRef]

38. Toledano, A.; Serrano, L.; Pineda, A.; Romero, A.A.; Luque, R.; Labidi, J. Microwave-assisted depolymerisation of organosolv lignin via mild hydrogen-free hydrogenolysis: Catalyst screening. Appl. Catal. B-Environ. 2014, 145, 43-55. [CrossRef]

39. Mauriello, F.; Paone, E.; Pietropaolo, R.; Balu, A.M.; Luque, R. Catalytic transfer hydrogenolysis of lignin-derived aromatic ethers promoted by bimetallic pd/ni systems. ACS Sustain. Chem. Eng. 2018, 6, 9269-9276. [CrossRef]

40. Friend, C.M.; Muetterties, E.L. Coordination chemistry of metal surfaces. 3. Benzene and toluene interactions with nickel surfaces. J. Am. Chem. Soc. 1981, 103, 773-779. [CrossRef] 
41. Xia, J.; He, G.; Zhang, L.; Sun, X.; Wang, X. Hydrogenation of nitrophenols catalyzed by carbon black-supported nickel nanoparticles under mild conditions. Appl. Catal. B-Environ. 2016, 180, 408-415. [CrossRef]

42. Luc, W.; Jiao, F. Synthesis of nanoporous metals, oxides, carbides, and sulfides: Beyond nanocasting. Acc. Chem. Res. 2016, 49, 1351-1358. [CrossRef] [PubMed]

43. Tian, C.; Li, J.; Ma, C.; Wang, P.; Sun, X.; Fang, J. An ordered mesoporous ag superstructure synthesized via a template strategy for surface-enhanced raman spectroscopy. Nanoscale 2015, 7, 12318-12324. [CrossRef] [PubMed]

(C) 2019 by the authors. Licensee MDPI, Basel, Switzerland. This article is an open access article distributed under the terms and conditions of the Creative Commons Attribution (CC BY) license (http://creativecommons.org/licenses/by/4.0/). 